\title{
Memahami Sastra Teenlit dengan Model Potong Naskah dan Membaca Kritis pada Mata Kuliah Pengkajian Cerkan Jurusan Sastra Indonesia Undip Semarang
}

\author{
Sukarjo Waluyo \\ Fakultas Ilmu Budaya, Universitas Diponegoro \\ sukarjowaluyo@gmail.com
}

\begin{abstract}
Teenlit tells the story of teenage social themes with simple and light language. Western culture and personality that became the main background was finally adopted by Indonesian youth. This is seen in their behavior and social life. However, teenlit can be used as an effective adolescent character education medium. This study explains the desired characteristics of adolescents. This can be seen when teenagers read teenlit with the model cut into scripts and critical reading. The method used in this research is descriptive analytical method. This method is used to identify the culture and personality of Western teenagers contained in teenlit. This study also uses observation to find out how adolescent responses are related to character education. Results from this study: 1) adolescent understanding of Western youth culture and personality; 2) adolescent understanding of Western youth culture and personality adopted from adolescents, among others: clothing and fashion, interpreting entertainment, and how to get along; 3 ) the expected formulation of teenage characters.
\end{abstract}

Keywords: Teenlit; teenager; culture; and personality.

\section{Intisari}

Teenlit bercerita tentang tema sosial remaja dengan sederhana dan bahasa ringan. Budaya dan kepribadian Barat yang menjadi latar utama akhirnya diadopsi oleh remaja Indonesia. Hal ini tampak dalam perilaku dan kehidupan sosial mereka. Namun, teenlit dapat digunakan sebagai media pendidikan karakter remaja yang efektif. Penelitian ini menjelaskan tentang karakter yang diinginkan remaja. Hal ini tampak saat remaja membaca teenlit dengan model potong naskah dan membaca kritis. Metode yang digunakan dalam penelitian ini adalah metode deskriptif analitis. Metode ini digunakan untuk mengidentifikasi budaya dan kepribadian remaja Barat yang terkandung dalam teenlit. Penelitian ini juga menggunakan observasi untuk mengetahui bagaimana tanggapan remaja terkait dengan pendidikan karakter. Hasil dari penelitian ini: 1) pemahaman remaja tentang budaya dan kepribadian remaja Barat; 2) pemahaman remaja tentang budaya dan kepribadian remaja Barat yang diadopsi dari remaja, antara lain: pakaian dan mode, menafsirkan hiburan, dan bagaimana bergaul; 3) perumusan karakter remaja yang diharapkan.

Kata kunci: Teenlit; remaja; budaya; dan kepribadian. 


\section{Pendahuluan}

Istilah teenlit berasal dari teenage literature yang berarti sastra untuk remaja. Sesuai dengan namanya, teenlit berkisah tentang remaja lengkap dengan segala tetek bengeknya, mulai dari kisah persahabatan, percintaan, hingga perbedaan pendapat dengan orang tua. Teenlit ditulis dengan bahasa yang ringan serta alur penceritaan yang sederhana. Fenomena teenlit ini tidak hanya ada di Indonesia. Novel-novel dengan genre teenlit menjadi pembicaraan di berbagai belahan dunia.

Genre ini bermula dari novel ringan yang dipelopori oleh Bridget Jones Diary karya Helen Fielding. Buku tersebut meledak di pasaran dan menghasilkan lebih dari US \$71 juta. Angka yang cukup fantastis untuk sebuah buku. Novel ini juga sempat diadaptasi ke versi layar lebar dengan judul yang sama dan dibintangi oleh aktris Renee Zelweger. Film ini masuk ke dalam jajaran Film Box Office dan masuk ke dalam nominasi Golden Globe. Sejak itu chicklit, genre yang menjadi cikal bakal teenlit, mulai mewabah di seluruh dunia, termasuk Indonesia. Ratusan judul buku teenlit sudah beredar di pasaran, termasuk juga karyakarya terjemahan dari penulis luar negeri.

Fenomena teenlit merebak di Indonesia sejak awal tahun 2000. Pada awal kemunculannya di Indonesia, teenlit banyak menimbulkan pertentangan karena dianggap sebagai karya yang minim pengetahuan dan tidak berkualitas. Sastra genre ini dianggap hanya berupa omong kosong. Bahkan banyak yang mendeskreditkannya dari pengertian karya sastra pada umumnya. Latar penceritaan yang mengadobsi kebudayaan dan kepribadian remaja Barat pun menjadi faktor ditentangnya keberadaan sastra teenlit di Indonesia. Namun pada kenyataannya, genre sastra ini justru semakin berkembang dari tahun ke tahun. Remaja yang menjadi konsumen pertama sastra teenlit mendapat bahan bacaan yang mampu mewakili kepribadiannya. Sastra teenlit mengangkat tema-tema sosial remaja dalam kehidupan seharihari dengan alur yang sederhana dan bahasa yang ringan. Karena hal tersebut, maka remaja dengan mudah menyerap hal apa saja yang terkandung dalam teenlit. Ada tiga buah teenlit yang akan menjadi data dalam artikel ini, yaitu 5 cm (2005) karya Dhony Dhirgantoro, Me \& My Prince Charming (2014) karya Orizuka, dan Claudia/Jasmine (2008) karya Maggie Tiojakin. 
Pola hidup dan kepribadian remaja yang diangkat dalam teenlit—sebagaimana tampak dalam ketiga karya teenlit tersebut di atas - adalah pola hidup dan kepribadian kaum urban yang diadobsi dari pola hidup remaja Barat. Hal ini berkaitan erat dengan stereotip masyarakat yang menganggap bahwa kehidupan remaja Barat adalah pola kehidupan modern. Oleh karena itu, baik secara langsung maupun tidak, remaja meniru pola sosial yang ada dalam teenlit. Dari sini muncullah anggapan bahwa remaja yang tidak meniru pola sosial kaum urban adalah remaja yang tidak mengikuti perkembangan zaman.

Teenlit memberi pesan yang secara halus disampaikan melalui alur sederhana dan bahasa yang ringan sehingga remaja yang menikmati sastra teenlit tidak merasa digurui. Dengan kata lain, teenlit menjadi media pendidikan yang efektif bagi remaja. Hal yang justru sulit diterapkan di sekolah atau kampus dengan segala macam teknik pengajaran dan basis kurikulum. Dengan demikian, maka teenlit mempunyai peranan yang penting dalam pembentukan stigma remaja tentang pola sosial dan kepribadiannya.

Teenlit pada akhirnya pembaca usia belasan tahun. Penyajian yang serupa buku harian, teknik pengisahan dan pilihan bahasa yang identik dengan kehidupan remaja dan anak sekolahan mampu membangkitkan keterlibatan pembaca. Dalam novel-novel teenlit, remajalah yang menjadi sentralnya. Pergaulan di sekolah, persahabatan berkelompok atau dalam istilah remaja disebut "geng", gaya hidup mewah dan glamour, masalah percintaan, dan kenakalan remaja adalah hal yang identik dalam novel-novel teenlit. Ida Rochani Adi (2001), seorang dosen sastra populer UGM, menjelaskan bahwa suatu karya sastra disebut populer diantaranya karena tema, cara penyajian teknik bahasa, dan penulisannya mengikuti pola umum yang tengah digemari masyarakat pembacanya, termasuk di Indonesia. Sastra populer tidak hanya sekadar menghibur, tetapi juga dinikmati sebagai karya seni. Sastra populer, terutama dalam bentuk novel, tidak saja dipandang sebagai barometer perkembangan sosial, budaya, dan ekonomi masyarakatnya, tetapi juga bagi masyarakat dunia. Telah banyak ahli membicarakan sastra populer dalam kaitannya dengan masyarakat, tetapi jelas pula bahwa banyak di antaranya sama sekali tidak bertolak dari gagasan adanya perbedaan antara yang populer dan elit dalam sastra.

Melihat berbagai fenomena remaja dan sastra teenlit di atas, novel-novel teenlit sebenarnya bisa dimanfaatkan untuk membentuk karakter remaja yang baik melalui teknik 
pengajaran di sekolah dan kampus dengan metode yang tepat. Hal inilah yang menjadi latar belakang peneliti untuk mengungkap fenomena teenlit dengan model potong naskah dan membaca kritis serta bagaimana kaitannya dengan pendidikan karakter di Fakultas Ilmu Budaya Undip Semarang.

Permasalahan yang akan diungkap dalam penelitian ini adalah bagaimanakah pemahaman remaja tentang kebudayaan dan kepribadian remaja Barat yang diadobsi dalam sastra teenlit, bagaimanakah pemahaman remaja tentang kebudayaan dan kepribadian remaja Barat yang diadobsi dalam sastra teenlit setelah menggunakan model potong naskah dan membaca kritis, dan rumusan karakter seperti apakah yang diharapkan remaja tentang kebudayaan dan kepribadian setelah membaca sastra teenlit dengan menggunakan model potong naskah dan membaca kritis.

\section{Metode Penelitian}

Metode yang digunakan untuk mencapai tujuan penelitian ini adalah metode analisis deskriptif. Metode tersebut digunakan untuk mengidentifikasi kebudayaan dan kepribadian remaja Barat yang terkandung dalam sastra teenlit. Penelitian ini menggunakan metode observasi dan analisis data untuk mengetahui pola pendidikan karakter remaja serta dampak dari kebudayaan dan kepribadian remaja dalam sastra teenlit. Data-data primer yang diperlukan diperoleh dari data-data pustaka yang ada dalam sastra teenlit, kuesioner terstruktur, dan observasi. Data yang berupa teks-teks sastra teenlit yang bisa dipastikan disukai remaja selanjutnya diberikan kepada remaja/mahasiswa. Melalui teknik membaca potong naskah akan didapatkan apa persepsi remaja tentang sastra teenlit dan isinya untuk kemudian didiskusikan yang mendapatkan persepsi yang benar.

\section{Hasil dan Pembahasan}

Sebuah karya sastra yang dihasilkan oleh seorang sastrawan tidak bisa dilepaskan dari hal-hal yang melingkupi kehidupannya, yaitu manusia dan segala macam segi kehidupannya. Karya sastra membicarakan manusia dan segala kompleksitas sifat dan problemnya. Melalui karya sastra, seorang pengarang mengungkapkan masalah-masalah kehidupan manusia dalam berinteraksi dengan orang lain atau lingkungannya. Kisah mengenai penderitaan manusia, 
perjuangan, kasih sayang, kebencian, nafsu, dan segala yang dialami manusia menjadi bahan mentah bagi terciptanya sebuah karya sastra. Hal ini sesuai dengan pernyataan Esten (1989:8) bahwa sebuah cipta sastra mengungkapkan masalah-masalah manusia dan kemanusiaan. Dengan sebuah cipta sastra pengarang ingin menampilkan nilai-nilai yang lebih tinggi dan agung, ingin menafsirkan tentang hidup dan hakikat hidup.

Karya sastra sebagai wadah penyampaian ide-ide yang dipikirkan dan dirasakan oleh pengarang tidak saja lahir dari masalah-masalah yang ada di dalam kehidupan lugas, melainkan juga dari kesadaran bahwa karya sastra merupakan cerita fiktif. Artinya, bahwa kelahiran karya sastra tidak hanya sebagai gambaran dari peristiwa yang terjadi di dalam lingkungan sekitar pengarang saja, melainkan sudah diolah dan dipadukan dengan imajinasi dan kreativitas pengarang sehingga memiliki nilai seni atau nilai sastra tertentu.

Teenlit adalah bagian sastra yang banyak dinikmati oleh para remaja. Beberapa yang menjadi kajian dalam penelitian ini adalah sebagai berikut.

\section{Novel $5 \mathrm{~cm}$}

Novel ini menceritakan persahabatan lima orang anak manusia bernama Arial, Riani, Zafran, Ian, dan Genta. Mereka berlima memiliki obsesi dan impian masing-masing. Lima sahabat ini telah menjalin persahabatan selama tujuh tahun. Suatu ketika mereka sudah jenuh dengan aktivitas yang selama ini mereka lakukan bersama. Terbersitlah ide untuk tidak saling bertemu dan berkomunikasi satu sama lain selama tiga bulan.

Dalam perjalanannya itulah mereka pada akhirnya menemukan arti dan makna manusia yang sesungguhnya. Perubahan itu dimulai dari pendidikan, karier, idealisme, dan cinta. Semuanya terkuak dalam sebuah perjalanan 'reuni' mereka mendaki puncak gunung tertinggi di Pulau Jawa, yaitu Mahameru. Dan disanalah cerita bergulir dan mereka berlima menyadari bahwa mereka bukan sekadar seonggok daging yang dapat berbicara, berjalan, dan mempunyai nama. Mereka pun pada akhirnya dapat menggapai cita-cita yang selalu mereka impikan. 


\section{Novel Me \& My Prince Charming}

Novel ini bercerita tentang kehidupan dunia remaja kisah-kasih dan percintaan anak-anak SMA yang penuh warna. Senang, sedih, marah, benci, kesal, dan gembira selalu silih berganti. Cherry Danisha adalah seorang gadis SMU 1 yang menjadi tokoh utama dalam novel tersebut. Ia tinggal bersama ayah serta bu dan kakak tirinya. Hingga pada akhirnya Andros, teman sekolah Adit - kakak Cherry - main ke Cherry dan Andros dimulai. Berawal dari sinilah akhirnya Cherry dan Andros akhirnya berpacaran.

Namun, kisah kasih mereka berdua dalam perjalanannya amat unik. Meski resmi berpacaran, Andros terlihat tidak mempunyai perhatian seperti biasanya orang berpacaran. Saat nonton bereng misalnya, Andros justru malah asyik dengan dirinya sendiri dan akhirnya malah tertidur. Cherry pada akhirnya sering kecewa dan 'ngambek'. Akan tetapi, Andros terlihat amat polos dan tidak memperbaiki diri. Ia diam dan pasif.

\section{Novel Claudia/Jasmine}

Novel Claudia/Jasmine menceritakan tentang lika-liku sebuah jalannya percintaan. Sejak SMA Clausia Jasmine sudah menjalin hubungan percintaan yang pada awalnya manis, tetapi harus mengalami pada akhirnya harus menghadapi masalah serius. Ia rela melepaskan mahkota keperawanannya yang menyebabkan hamil, sementara lelaki yang menghamilinya kemudian lari meninggalkannya.

Sejak itulah, Clausia Jasmine mengalami trauma untuk mengenal lebih dekat lakilaki atau menjalin hubungan serius untuk menuju pintu pernikahan hingg usia 30 tahun. Padahal ia adalah sosok perempuan yang cantik dan memiliki badan idel yang membuatnya disukai banyak laki-laki. Pada akhirnya ia bertemu seorang laki-laki tampan, mapan, dan lebih muda darinya yang bernama Jerry. Perjalanan cintanya dengan Jerry juga tidak lepas dari dari masalah dan pertengkaran. Akan tetapi, pada akhirnya mereka bisa bersatu kembali.

Pada saat tokoh Claudia Jasmine mengalami masalah berat, dalam novel ini diceritakan bagaimana sahabat dan keluarganya selalu memberikan motivasi, saran, dan dukungan. Perjuangan seorang perempuan dalam menjalani kehidupan dan mengejar karier menjadi sorotan dalam novel ini. Tokoh Claudia Jasmine adalah sosok wanita yang kuat meskipun pernah terjatuh dalam lubang yang dalam. 


\section{Pemahaman Remaja tentang Kebudayaan dan Kepribadian Remaja Barat yang Diadobsi dalam Sastra Teenlit}

Berdasarkan pengamatan peneliti dalam diskusi dan wawancara dengan mahasiswa semester 1 (40 mahaiswa) FIB pada sebuah kelas menggambarkan bahwa masalah kebudayaan dan kepribadian remaja pada umumnya masih sangat beragam dan bias. Dalam diskusi dan mengemukakan argumentasi pada umumnya mereka tidak ada referensi dan ukuran yang jelas.

Mereka pada akhirnya memaklumi dengan tidak ada ukuran yang pasti mengenai persepsi tentang kebudayaan dan kepribadian remaja. Mereka akan permisif jika ada teman lain yang memiliki persepsi berbeda. Pada umumnya menafsirkan bahwa kebudayaan dan kepribadian remaja barat yang mereka adopsi dari sastra teenlit adalah representasi dari modernitas dan kemajuan. Mereka sangat percaya dan yakin bahwa apa yang menjadi topik pembicaraan dan gaya hidup, seperti model pakaian, model rambut, cara bergaul, cara makan, kompensasi mencari hiburan, bahkan berpacaran akan menjadi fenomena remaja di Indonesia, termasuk bagi mahasiswa FIB Semarang.

Yang menarik beberapa mahasiswa menyadari bahwa kebudayaan dan kepribadian remaja yang mereka adopsi adalah barang dari luar yang belum tentu sesuai dengan kebudayaan dan kepribadian di Indonesia yang menganut adab "orang Timur". Namun, mereka juga mengakui bahwa referensi mereka tentang kebudayaan dan kepribadian Timur juga menjadi semakin bias. Ia justru umumnya mengeluhkan jika mereka sulit membayangkan bagaimanakah representasi menjadi remaja ideal dari dunia Timur itu? Sementara itu, kebiasaan, tradisi, dan adat dalam perhubungan dunia global seringkali dianggap kolot dan lebih menarik jika dihargai sebagai barang seni belaka.

Alhasil, cara berpakaian, cara makan, cara bergaul, model rambut, dan cara berpikir orang-orang tua bagi sebagian mahasiswa hanya dianggap sebagai barang seni yang mereka akui ketinggian moralitas dan cita rasanya, tetapi tidak merepresentasikan zamannya.

\section{Pemahaman Remaja tentang Kebudayaan dan Kepribadian Remaja Barat yang Diadobsi dalam Dastra Teenlit setelah Menggunakan Model Potong Naskah dan Membaca Kritis}


Pemahaman mahasiswa FIB mulai berubah pada diskusi pertemuan berikutnya. Beberapa mahasiswa yang diberikan kesempatan mempresentasikan makalah singkatnya tentang novel yang dipotong pada halaman yang sudah dipilih. Selanjutnya, hal ini memberikan suasana diskusi dan debat semakin beragam. Diskusi memunculkan masalah dari berbagai tema yang merepresentasikan kebudayaan dan kepribadian remaja barat dari beberapa novel teenlit yang terpilih. Beberapa hall tersebut antara lain.

\section{Pakaian dan Mode}

Dalam ketiga novel terpilih (5cm, Me \& My Prince Charming, dan Claudia/Jasmine) menunjukkan bahwa pakaian dan mode merepresentasikan hal yang terbaru. Hal ini menjadi trend di kota besar (khususnya Jakarta sesuai dengan latar utama ketiga novel tersebut). Debat dan diskusi serta wawancara yang peneliti lakukan menunjukkan bahwa para mahasiswa FIB menyadari bahwa apa yang menjadi trend pakaian dan mode dalam novel-novel tersebut adalah bentuk kesadaran remaja untuk bisa tampil modern. Kelebihannya adalah bahwa trend tersebut sangat simple dan sporty. Hal ini rasanya sesuai tuntutan emosi remaja yang identik dengan jiwa pemberontak dan anti-mainstream.

"Tidak ada masalah sebenarnya, asal tetap menutup aurat dan memenuhi standar etika dan moral. Sayang, hal ini juga masih bias dalam menentukan standar apa itu definisi aurat dan etika moral," demikian kira-kira pendapat umum diskusi. Namun, dengan model membaca potong naskah dan membaca kritis yang dilanjutkan dengan wawancara diperoleh sebuah kesimpualan bahwa pemahaman mahasiswa FIB makin kritis dan apresiatif. Mereka menyadari bahwa dari naskah yang terpotong mendapatkan kesempatan tidak hanya sebagai pembaca pasif belaka. Mereka bisa menfasirkan sendiri dan membandingkan dengan realitas sosial budaya di sekitarnya.

\section{Cara Memaknai Hiburan}

Dalam ketiga novel terpilih (5cm, Me \& My Prince Charming, dan Claudia/Jasmine) menunjukkan bahwa hiburan yang bersifat konsumtif, pragmatis, dan sangat hedonistik merepresentasikan kehidupan remaja kota yang terbaru. Hal ini menjadi trend di kota besar (khususnya Jakarta sesuai dengan latar utama ketiga novel tersebut). Hal ini tampak dalam 
teknologi sebagai perangkat komunikasi dan relasi sosial. Kafe dan tontonan seronok yang hanya melampiaskan jiwa kebebasan tanpa batas. Singkat kata, hampir tidak ada rambu-rambu yang jelas memaknai dan mendefinisikan lagi perihal hiburan.

Debat dan diskusi serta wawancara yang peneliti lakukan menunjukkan bahwa para mahasiswa FIB menyadari bahwa apa yang menjadi sarana dan trend hiburan dalam novelnovel teenlit tersebut adalah bentuk kesadaran remaja untuk bisa tampil bebas dan modern. Kesimpulan umumnya, hiburan tersebut sangat menggambarkan kebebasan tanpa batas dan seringkali terjebak dalam perbuatan yang tidak sesuai dengan budaya timur seperti film porno, narkoba, dan pergaulan bebas.

\section{Cara Bergaul}

Dalam ketiga novel terpilih (5cm, Me \& My Prince Charming, dan Claudia/Jasmine) menunjukkan bahwa cara bergaul meresentasikan hal yang sudah dianggap umum di kota-kota besar. Hal ini dapat terlihat dari cara bergaul dengan sesama teman yang hampir menafikkan nilai kesopanan. Mereka bergaul hanya untuk kebutuhan aktualisasi dan mengisi waktu, serta menyalurkan hobi dari tekanan dan beban berat kehidupan remaja kota. Pelajaran dan tugas sekolah yang sulit, gaya hidup yang materialistik dan cenderung individualistik, serta kebisingan dan kemacetan yang membuat mereka membutuhkan kompensasi. Sementara ruang publik hampir-hampir sudah hilang.

Debat, diskusi, dan wawancara yang peneliti lakukan menunjukkan bahwa para mahasiswa FIB menyadari bahwa apa yang menjadi cara pergaulan remaja membutuhkan standar dan tujuan yang jelas. Tuntutan emosi remaja yang identik dengan jiwa pemberontak dan anti-mainstream, tetap harus membangun komunitas positif dan bermanfaat bagi remaja dan masyarakat. Dengan model membaca potong naskah dan membaca kritis yang dilanjutkan dengan wawancara diperoleh sebuah kesimpualan bahwa pemahaman mahasiswa FIB makin kritis untuk menafsirkan sendiri dan membandingkan pergaulan yang ada dalam novel-novel teenlit dengan realitas sosial-budaya di sekitarnya. 


\section{Rumusan Karakter yang Diharapkan Remaja tentang Kebudayaan dan Kepribadian setelah Membaca Sastra Teenlit Menggunakan Model Potong Naskah dan Membaca Kritis}

Diskusi yang memunculkan masalah dari berbagai tema yang merepresentasi kebudayaan dan kepribadian remaja Barat dari beberapa novel teenlit yang terpilih pada akhirnya membuat para mahasiswa sadar. Mereka pada akhirnya mampu merumuskan rumusan karakter dan kepribadian yang sesuai dengan realitas sosial-budaya di sekitarnya. Seelah membaca sastra teenlit menggunakan model potong naskah dan membaca kritis mereka mampu merumuskan karakter dan kepribadian remaja ideal sebagai berikut.

\section{Pakaian dan Mode}

Cara berpakaian dan mode dalam novel-novel teenlit pada umumnya berasal dari cara berpakaian dan mode remaja Barat yang berbeda latar sosial-budaya berbeda dengan Indonesia. Remaja boleh membaca novel-novel teenlit, tetapi yang lebih penting adalah belajar dari bagaimana tokoh-tokoh dalam cerita tersebut membangun sebuah prestasi dan memecahkan masalah-masalah kehidupan. Bagaimanapun sastra mempunyai adagium 'mendidik dan berguna'. Jadi, sastra melalui tokoh-tokohnya pasti mampu menyelipkan pesan moral positif bagi para pembacanya.

\section{Cara Memaknai Hiburan}

Cara memaknai hiburan dari para tokoh-tokohnya (dalam novel-novel teenlit) belum tentu sesuai dengan sosial budaya masyarakat Indonesia. Cara memaknai hiburan dengan nongkrong di kafe dan menonton film porno misalnya, tentu sangat tidak sejalan denga realitas dan konteks sosial-budaya masyarakat Indonesia, terutama masyarakat di daerah yang masih mengharapkan remaja untuk bisa mendapatkan pendidikan karakter. Pendidikan agar memiliki masa depan yang baik dan bisa membangun daerahnya di masa yang akan datang.

\section{Cara Bergaul}

Cara bergaul dalam novel-novel teenlit tentu juga belum tentu sesuai dengan latar belakang sosial-budaya masyarakat setempat. Cara berpacaran dalam novel misalnya, tidak bisa 
langsung menjadi rujukan para remaja, khususnya remaja daerah yang masyarakatnya masih teguh menjunjung tinggi sopan-santun dan adat budaya setempat. Meskipun kita boleh membaca novel-novel teenlit, tetapi yang lebih penting adalah belajar dari bagaimana tokohtokoh dalam cerita tersebut membangun dan mengukir sebuah prestasi bagi masa depannya. Hubungan remaja putra dan remaja putri dalam latar sosial-budaya masyarakat Indonesia, tentu saja hal yang masih tabu dan sebaiknya dihindarkan.

\section{Simpulan}

Sebuah karya sastra yang dihasilkan oleh seorang sastrawan tidak bisa dilepaskan dari hal-hal yang melingkupi kehidupannya. Seorang pengarang mengungkapkan masalah-masalah kehidupan manusia dalam berinteraksi dengan orang lain atau lingkungannya. Karya sastra sebagai wadah penyampaian ide-ide yang dipikirkan dan dirasakan oleh pengarang tidak saja lahir dari masalah-masalah yang ada di dalam kehidupan lugas, melainkan juga dari kesadaran bahwa karya sastra merupakan cerita fiktif. Artinya, bahwa kelahiran karya sastra tidak hanya sebagai gambaran dari peristiwa yang terjadi di dalam lingkungan sekitar pengarang saja, melainkan sudah diolah dan dipadukan dengan imajinasi dan kreativitas pengarang, latar belakang sosial-budaya pengarang, dan tujuan dari penerbitan karya tersebut.

Pembacaan karya sastra oleh pembaca dari latar belakang sosial budaya yang berbeda membutuhkan reinterpretasi. Model pembacaan sastra reinterpretasi bisa dilakukan dengan model potong naskah dan membaca kritis. Model ini bisa digunakan dalam pembacaan novelnovel teenlit yang umumnya mengusung budaya Barat oleh pembacaan remaja dari masyarakat Indonesia yang sebagian besar berada di daerah. Model potong naskah dan membaca kritis yang dilakukan pada sebuah kelas pada mahasiswa FIB Undip menghasilnya beberapa reinterpretasi yang berkaitan dengan: 1) pakaian dan mode; 2) cara memaknai hiburan; dan 3) cara bergaul. 


\section{Daftar Pustaka}

Adi, Ida Rochadi. 2011. Fiksi Populer: Teori dan Metode Kajian. Yogyakarta: Pustaka Pelajar.

Anggun, Arfyani Rani 2003. Minat, Motif, Tujuan, Manfaat Membaca Teenlit dan Peran Perpustakaan: Studi Kasus Mahasiswa Jurusan Sastra Indonesia Pengguna Perpustakaan Fakultas Ilmu Budaya Universitas Diponegoro Semarang. Semarang: Undip.

Anggun, Radyan Pramesthi. 2011. Pemanfaatan Teenlit sebagai Alternatif Bahan Pembelajaran Apresiasi Sastra untuk Siswa SMA. Semarang: Unnes.

Dhirgantoro, Dhony. 2005. 5 cm. Yogyakarta: Grasindo.

Dwi, P. Maria. 2007. "Motif, Tujuan, dan Manfaat Siswa Membaca Karya Sastra Populer Jenis Teenlit”. Skripsi S1. Fakultas Sastra Universitas Diponegoro Semarang.

Kusmarwanti. 2005. "Teenlit dan Budaya Menulis di Kalangan Remaja". Makalah yang disajikan dalam Seminar Nasional PIBSI XXVII tanggal 27-28 September 2005 di Universitas Negeri Yogyakarta.

Mulyana, Rahmat. 2004. Mengartikulasikan Pendidikan Nilai. Bandung: Alfabeta.

Orizuka. 2014. Me \& My Prince Charming. Jakarta: Puspa Swara.

Phenix, Philip. 2001. Realm of Meaning: McGraw-Hill Book Company. New York San Francisc Toronto London.

Tiojakin, Maggie. 2008. Claudia/Jasmine. Jakarta: Gagasmedia.

Tylor, E.B. 1974. Primitive Culture: Researches Into The Development of Mythology, Philosophy, Religion, Art, and Custom. New York: Gordon Press. First Published in 1871. 